\title{
A Cross-disciplinary Investigation of Project Team Functioning
}

\section{Prof. Margaret Garnett Smallwood, University of Texas at Dallas}

Margaret Garnett Smallwood is an associate professor of practice in business communications in the Jindal School of Management at The University of Texas at Dallas. She teaches undergraduate business communication courses and an MBA communication course. Margaret earned her MBA from UTD in 2010, and completed her Master's in Communication Studies from Sam Houston State University in 2020. She previously worked in public relations, journalism, and corporate communications for major corporations and operated her own communications consulting firm.

\section{Dr. Robert Hart P.E., University of Texas at Dallas}

Robert Hart is an Associate Professor of Practice in the Mechanical Engineering Department at the University of Texas at Dallas (UTD). He teaches the capstone design course sequence and serves as a Director for the UTDesign program, which facilitates corporate sponsorship of capstone projects and promotes resource sharing and cross-disciplinary collaboration among engineering departments. His professional interests are in the areas of engineering education, fluid mechanics, and thermal science. He is an active member of ASME and ASEE and has been a member of the Capstone Design Conference organizing committee since 2015. Before joining UTD, he worked as an engineer for 10 years, primarily at Southwest Research Institute. He is a licensed professional engineer and holds a B.S. and M.S. degree in mechanical engineering from the University of Houston and a Ph.D. degree in Mechanical Engineering from the University of Texas at Austin.

\section{Dr. Todd W. Polk, University of Texas at Dallas}

Dr. Todd Polk is an Associate Professor of Practice in the Bioengineering Department at the University of Texas at Dallas. He has a Bachelor of Science degree in Electrical Engineering from Texas A\&M University. He received his Master of Science and Doctoral degrees in Electrical Engineering from the University of Texas at Dallas. Todd has over 25 years of industry experience in design, test, applications, sales and management. After joining UT Dallas in 2013, he developed the capstone course sequence in the newly-formed Bioengineering department and has been responsible for teaching it since. Todd also serves as a Director for the UTDesign program, which facilitates resource sharing and corporate sponsorship of projects for all engineering disciplines at the university. He attended the Capstone Design Conference in 2014, 2016 and 2018 and is a member of the conference's organizing committee. He is an active member of IEEE and EMBS. 


\title{
A Cross-Disciplinary Investigation of Project Team Functioning
}

\begin{abstract}
This paper examines the effectiveness of teams in two distinct cohorts at the same university: engineering students enrolled in a Senior Design Capstone class, and business students enrolled in a business communication course. Both cohorts received identical professional communication training on teamwork, conflict management, presentations, and team leadership. Both groups worked on similarly sized long-term project teams and completed the same pre- and post-surveys to assess how their teams were functioning. The results point to differences and similarities in how students from two different disciplines function on a project team. We identify some characteristics that make a project team successful that are not common to both disciplines. These results point to opportunities for educators to improve the educational experience of student teams in both disciplines.
\end{abstract}

\section{Introduction}

At our university, mechanical and biomedical engineering students are enrolled together in the same two-semester capstone project class. Students work on single- or mixed-discipline teams to develop a prototype device to solve a problem for a client that provides funding. Each project meets the client's unique needs and provides students with practical engineering experience. The client works closely with students throughout the process and receives the completed project after the course ends. At the same university, business students in a Business Communication (BCOM) course work in teams on a hypothetical Corporate Social Responsibility (CSR) project. Students identify a social need in their community and develop a plan to address the problem. Teams also identify companies that could be interested in funding the project. While the project is hypothetical, it mirrors actual CSR efforts undertaken by organizations to enhance their reputations and images.

As papers presented at recent ASEE conferences show [1], engineering students, just like business students and students from nearly any major, need to develop professional communication skills. To address this need, a partnership between the engineering and business schools has made it possible for the engineering students to receive specialized training in this area [2]. Launched in 2014 and refined each semester subsequently, this training program is designed and delivered consistently with the literature on teaching workplace skills to undergraduate students.

As a result, engineering students in the capstone course and business students in a business communication course at the same university receive identical professional communication 
training in teamwork skills, conflict management techniques, presentation skills, and team leadership from the same communications instructor. The goal is to help students develop professional skills considered essential by employers who hire new college graduates. Each year, the National Association of Colleges and Employers' (NACE) Job Outlook survey analyzes which career readiness competencies employers value most in their new college hires [3]. Employers rank each competency as more than essential, essential, or somewhat essential in the survey. In the Job Outlook 2019 Survey, employers ranked critical thinking, oral and written communication, teamwork and collaboration skills, and professionalism/work ethic as more than essential competencies in new hires [3]. While the training in this project did not address the critical thinking competency, it addressed the other top three skills cited in the NACE survey: oral and written communication, teamwork and collaboration skills, and professionalism/work ethic.

Recognizing that we had two groups from distinctly different disciplines that shared a similar academic experience (i.e., working on a significant project while receiving identical communication skills training), we were interested to see whether and how these two groups differed in how they functioned on teams. We compared the results of a team effectiveness survey that we were already using in the classes to address this research question. We viewed this as an opportunity to share best practices across disciplines in cases where we identified strengths in team functioning that were not common to students in both groups. It is worth noting that several sources describe our university as highly diverse in its student population, and teams in both cohorts also were highly diverse [4].

\section{Communication Skills Training}

The communication skills training is delivered in an interactive lecture setting during several sessions throughout the course. Team dynamics and teamwork are covered shortly after team formation. Team conflict and resolution are deferred until later in the semester, when students are more likely to face these issues. Additional sessions provide training on presentation skills for all students and mentoring to team leaders. More details on the sessions are provided below.

\section{Teamwork}

Teamwork training - the first aspect of the communication training - began early in the semester, soon after group formation. Instructors assigned the students in each cohort to teams of between five and six members, and each team selected a leader. In the first few weeks of the semester, the communications instructor gave an interactive presentation about the criticality of developing a robust and detailed team charter unique to each team's goals and personality. As Cox and Bobrowski [5] noted, the team charter assignment helps groups bond more quickly and 
function more effectively. In this research project, the teamwork training session explored the charter's aspects such as team capabilities, management, rules, and goals. Next, students completed individual questionnaires and then shared their responses with their team members. For example, the team management questionnaire explored how a student personally dealt with conflict on a team, which person or persons the student wanted to be responsible for resolving conflicts, and whether harmonious team relationships, team and individual success, or open communication were most important to the individual.

During the teamwork session, students in each cohort also performed skits about typical teamwork issues, such as non-contributing teammates and members who were always late to team meetings. While amusing, the skits provoked general class discussion about effective and ineffective ways to resolve team communication problems. The session concluded with team members applying the material as they worked on their team charters.

Beyond the importance of a team charter unique to each group's goals and personality, the teamwork training also covered team communication, understanding and accepting differences, setting clear goals, and other facets of effective teams. This project's teamwork training reflects practices recommended in the literature on teaching teamwork skills to students. For example, Riebe, Roepen, Santarelli, and Marchioro [6] described a three-phase approach to teaching teamwork skills to undergraduate students. Their methods paralleled techniques deployed in this project. The techniques used by Riebe et al. [6] included questionnaires to guide team members about expected behaviors, surveys to provide feedback loops to students, and assessments of team skill levels. Noting the importance teamwork skills may have on a student's future career success, Riebe and her colleagues concluded that it is crucial to provide students across disciplines with this kind of training.

\section{Presentation Training}

The second aspect of communication training was an entire class session about presentations: what comprises a successful presentation, how to analyze and engage an audience, and how to create compelling presentation materials. Students in both cohorts watched David J.P. Phillips' [7] Ted Talk on "How to Avoid Death by PowerPoint," which provides five critical tips for successful presentations. Students then met in their teams to discuss and analyze Phillips' [7] presentation. The cohorts also critiqued recorded presentations from other students, which resembled the students' presentations. The engineering students reviewed and analyzed an engineering capstone presentation from another university. The business communication students watched and assessed a presentation from an earlier student team for the same CSR project assignment. 
The literature regarding teaching presentation skills to students includes Stuart's case study [8], which reviewed techniques used in a graduate presentation skills class. Stuart suggested that these techniques be adapted to presentation classes for undergraduates as well. Her class utilized techniques such as video recording of student presentations for later review by the student, peer rehearsals, and assessments of PowerPoint slides. Stuart's graduate class established two fundamental rules for student presentations. First, every aspect of the presentation's preparation and delivery should reflect respect for the audience, and second, student presentations need to be "carefully prepared, practiced, critiqued and refined" [7, p. 15]. Stuart urges instructors in a wide range of disciplines to set these same expectations for undergraduate student presentations.

The presentation training provided to both cohorts in this project implements Stuart's [8] recommendations. Teams in both cohorts received detailed grading rubrics by which instructors would evaluate their presentations. The business cohort gave practice presentations in class, and each team received feedback from both peers and the instructor. Engineering students were encouraged to practice their presentations outside of the classroom. Final presentations in both cohorts were recorded and evaluated according to the rubrics. Teams also received extensive feedback from instructors and peers about their final presentations.

\section{Conflict Management Training}

The third aspect of the training, addressing conflict management, was provided once teams had worked together for several weeks. The communication instructor gave an interactive presentation about identifying conflict types, clarifying its sources, examining common responses to conflict, and exploring positive and negative ways to resolve conflict. Again, student skits were incorporated to engage students and reinforce the material. During the session, teams met to discuss whether gender and cultural differences in teamwork and conflict exist.

The classroom discussion also applied this information to the specific projects the students were assigned. The instructor asked students what kinds of conflict they might experience at specific stages of their projects. The goal was to help students identify constructive versus destructive conflict and to know what kinds of conflict may surface at various times. The overarching goal was to arm students with the tools they need to resolve conflict on their teams.

Returning to the academic literature on helping students work effectively on teams, the approach to conflict management training in this project recalls the work of Riebe, Roepen, Santarelli, and Marchioro [6]. Riebe and her colleagues recommended that instructors provide students with a useful, practical conceptual framework of how teams function, letting groups know that teams cycle through predictable phases. The Riebe et al. model [6] incorporated Tuckman and Jensen's [9] stages of team development, including forming, norming, storming, and performing stages. The communications training in this project provided such a conceptual framework for students. 


\section{Team Health Check}

The Team Health Check (THC) survey was administered to two cohorts of engineering capstone class students and one cohort of BCOM students from the Summer 2019 semester to the Spring 2020 semester. Each cohort was surveyed twice, yielding a total of six data sets. Students in each cohort completed the THC survey a few weeks after team formation and repeated it ten weeks later.

Each team's individual members completed an anonymous, 19-item Team Health Check developed by Briggs [10]. The THC form is included in the Appendix. Corporations have deployed such checks since Spotify adopted its Squad Health Check Model [11] in 2014. Many models of team health checks are available online or from management consulting firms [12], [13], [14]. This project used the Briggs team health check because of its breadth and scope and previous use with student teams [10]. This health check posed several questions in six categories: the team's Purpose and Direction, Leadership, Processes, Understanding Differences, Communication, and Relationships [10]. Students answer each question using a six-point scale: 6=Strongly Agree, 5=Agree, 4=Slightly Agree, 3=Slightly Disagree, 2=Disagree, and 1=Strongly Disagree. As mentioned above, this study did not directly address students' critical thinking skills as the Briggs' question set did not explore critical thinking.

The results of the health checks were aggregated and analyzed per team and shared with the team leads at the leadership session, which is discussed next.

\section{Team Leadership Training}

The final aspect of communication training provided to the cohorts in this project was a team leader-only coaching session held four weeks after students completed the first team health check survey. In each cohort, teams selected their team lead. Engineering and BCOM team leads fulfilled similar roles, such as distributing tasks, acting as an informal project manager, and guiding the team's work. The engineering team leads also served as points of contact with outside parties, such as sponsoring clients and mentors. Because both engineering and BCOM team leads occupied a unique position of leading a team over which they had no institutionalized or formalized authority, instructors decided that team leadership training would help support the leads and assist them in learning their responsibilities and roles.

In the team leadership session, leaders who had scored high on certain team health check items shared their best practices. Without identifying the low-scoring team leads, the session's goal was to encourage the adoption of effective team leaders' practices and for leaders to provide peer coaching. Leaders read articles about the difference between leading and managing and discussed where they were leading or managing their teams. Team leaders also watched and 
discussed a video from a business leader about empowering teams and had an open discussion about specific leadership challenges they faced.

The approach taken in the team leadership training is consistent with the recommendations from Gott, Bauer, and Long [15] about developing leadership in students. Gott et al. [15] suggested that instructors treat students as colleagues rather than learners. Taking this approach can help students develop their own identity as leaders and fill the gap between students' technical education and leadership development. An additional benefit of the approach recommended by Gott, Bauer, and Long [15] is that it prepares students as future professionals, regardless of what field they enter.

\section{Results}

For the analysis which follows, the individual responses from the first survey administration in both engineering cohorts have been combined into a single data set. Likewise, the responses from the second engineering class survey administration have been combined. These datasets are referred to as ENG \#1 and ENG \#2, respectively. The results from the first and second administration in the BCOM class are labeled as BCOM \#1 and BCOM \#2, respectively. Except for one instance in the engineering class, surveys were completed online by students independently in the Qualtrics system. Students using a live polling tool (TurningPoint from Turning Technologies) independently completed the first survey for one of the engineering cohorts in class.

For each survey participant, the responses to the questions in each THC category were averaged. This step yielded six average ratings for each participant corresponding to the THC categories of Purpose and Direction, Team Leadership, and the other categories. The results are summarized in Table 1, which shows the number of participants, mean, and standard deviation in each THC category for the four groups surveyed. The results for the THC categories were compared using an independent-samples, two-tailed t-test with unequal variance. The results are shown in Table 2. Significance was determined using an alpha level of .05 for all t-tests, and p-values less than .05 are highlighted in the table.

Table 1: Descriptive statistics for each category of the four Team Health Check surveys. $\mathrm{N}$ is the number of responses, $\mathrm{M}$ is the mean rating, and $\mathrm{SD}$ is the standard deviation of the ratings.

\begin{tabular}{|c|c|c|c|c|c|c|c|c|c|c|c|c|c|c|c|c|c|c|}
\hline & \multicolumn{3}{|c|}{$\begin{array}{c}\text { Purpose \& } \\
\text { Direction }\end{array}$} & \multicolumn{3}{|c|}{ Team Leadership } & \multicolumn{3}{|c|}{ Processes } & \multicolumn{3}{|c|}{$\begin{array}{l}\text { Understanding } \\
\text { Differences }\end{array}$} & \multicolumn{3}{|c|}{ Communication } & \multicolumn{3}{|c|}{ Relationships } \\
\hline & $N$ & $M$ & $S D$ & $N$ & $M$ & $S D$ & $N$ & $M$ & $S D$ & $N$ & $M$ & $S D$ & $N$ & $M$ & $S D$ & $N$ & $M$ & $S D$ \\
\hline ENG \#1 & 278 & 5.33 & 0.66 & 278 & 5.17 & 0.76 & 278 & 4.83 & 0.87 & 278 & 4.84 & 0.90 & 277 & 5.13 & 0.88 & 278 & 5.25 & 0.73 \\
\hline ENG \#2 & 201 & 5.31 & 0.70 & 201 & 5.12 & 0.89 & 201 & 4.90 & 0.85 & 201 & 4.91 & 0.91 & 201 & 5.10 & 0.77 & 201 & 5.21 & 0.72 \\
\hline BCOM \#1 & 106 & 5.18 & 0.74 & 106 & 5.30 & 0.64 & 106 & 5.06 & 0.62 & 106 & 5.11 & 0.77 & 105 & 5.46 & 0.52 & 104 & 5.35 & 0.62 \\
\hline ВсOM $\# 2$ & 93 & 5.40 & 0.79 & 93 & 5.16 & 1.06 & 93 & 5.20 & 0.86 & 92 & 5.22 & 0.97 & 92 & 5.20 & 0.96 & 92 & 5.28 & 0.97 \\
\hline
\end{tabular}


Table 2: Summary of p-values resulting from t-tests performed to compare the means of the THC surveys. Highlighted cells show results that are significant at an alpha level of .05 or less.

\begin{tabular}{|r|c|c|c|c|c|c|}
\hline & $\begin{array}{c}\text { Purpose \& } \\
\text { Direction }\end{array}$ & Team Leadership & Processes & $\begin{array}{c}\text { Understanding } \\
\text { Differences }\end{array}$ & Communication & Relationships \\
\cline { 2 - 8 } ENG \#1 vs. BCOM \#1 & .058 & .106 & .005 & .004 & $<.001$ & .184 \\
\cline { 2 - 7 } ENG \#2 vs. BCOM \#2 & .342 & .709 & .006 & .010 & .397 & .544 \\
ENG \#1 vs. ENG \#2 & .675 & .474 & .364 & .402 & .725 & .627 \\
\cline { 2 - 8 } \\
\cline { 2 - 8 }
\end{tabular}

When we compare the engineering and $\mathrm{BCOM}$ classes, we see that the same two categories of the THC (Process and Understanding Differences) meet the criteria for statistical significance at both survey points (\#1 and \#2). Additionally, Communication was identified as significant in only the first THC. There were no statistically significant categories when comparing the results for the first and second survey administrations in the engineering class. However, two categories (Purpose \& Direction and Communication) in the BCOM class showed statistical significance between the two survey points.

To gain more insight into the factors driving the differences, we performed a chi-square test to determine if the results for each question were independent of the groups being compared (i.e., ENG \#1, BCOM \#1). The results are shown in Table 3. Significance was determined using an alpha level of .05 for all chi-square tests, and p-values less than .05 are highlighted in the table. Question numbers (e.g., Q1, Q2) refer to the THC questions shown in the Appendix. The blanks in the table correspond to cases in which a chi-square statistic could not be computed due to zero responses in one or more of the scale levels (i.e., Slightly Disagree) for a question.

Table 3: Summary of p-values resulting from chi-square tests performed to compare individual question responses on THC surveys. Highlighted cells show results that are significant at an alpha level of .05.

\begin{tabular}{|c|c|c|c|c|c|c|c|c|c|c|c|c|c|c|c|c|c|c|c|}
\hline & \multicolumn{3}{|c|}{$\begin{array}{l}\text { Purpose \& } \\
\text { Direction }\end{array}$} & \multicolumn{3}{|c|}{ Team Leadership } & \multicolumn{4}{|c|}{ Processes } & \multicolumn{3}{|c|}{$\begin{array}{l}\text { Understanding } \\
\text { Differences }\end{array}$} & \multicolumn{3}{|c|}{ Communication } & \multicolumn{3}{|c|}{ Relationships } \\
\hline & Q1 & Q2 & Q3 & Q4 & Q5 & Q6 & Q7 & Q8 & Q9 & Q10 & Q11 & Q12 & Q13 & Q14 & Q15 & Q16 & Q17 & Q18 & Q19 \\
\hline ENG \#1 vs. BCOM \#1 & .002 & .341 & .932 & .118 & .755 & .046 & .707 & .498 & $<.001$ & .031 & .049 & .015 & .468 & .004 & .004 & .289 & - & .207 & .304 \\
\hline ENG $\# 2$ vs. BCOM $\# 2$ & - & .130 & .810 & .335 & .232 & .145 & .271 & .089 & .032 & .008 & .024 & $<.001$ & .010 & - & .128 & .029 & .269 & .009 & .003 \\
\hline ENG \#1 vs. ENG \#2 & .608 & .586 & .592 & .093 & .239 & .727 & .470 & .324 & .202 & .602 & .290 & .600 & .549 & .220 & .860 & .057 & - & .826 & .798 \\
\hline BCOM $\# 1$ vs. BCOM $\# 2$ & - & - & .249 & .052 & .279 & .012 & .424 & .001 & - & - & .447 & .078 & - & - & .004 & .023 & - & .089 & .046 \\
\hline
\end{tabular}

Within the Team Health Check categories, the Processes section includes Questions 7-10, and Understanding Differences includes Questions 11-13. Testing the statistical significance of the differences between groups (i.e., Eng \#1 vs. BCOM \#1), we find that Questions 9 and 10 from Processes and Questions 11 and 12 from Understanding Differences show a significant relationship for both the engineering and BCOM class comparisons. Various other questions also show a significant relationship and are likely the drivers of the differences seen in Table 2. 


\section{Discussion}

Questions arise about explaining the differences between the engineering and BCOM cohorts in terms of each group's team health check scores and scores on the check's six specific areas. Questions also emerge as to what educators can learn from these results to improve student teams' educational experience in both disciplines.

One possible explanation for different team health check responses from the two disciplines stems from differences in the cohorts themselves. First, engineering students at this university were slightly more than a year older than the BCOM students, with the mean age of the engineering respondent 23.1 years compared to the BCOM student's mean age of 22.0 years. (The standard deviations of the ages were 2.8 and 3.5 for the engineering and BCOM students, respectively.) Additionally, the gender mix for the engineering cohort was three-to-one male to female, while the BCOM cohort was two-to-one female to male.

Second, students in the engineering capstone class major in biomedical and mechanical engineering. While these different engineering areas certainly are distinct, there is a much more pronounced range of majors for the BCOM class. Regardless of their major, all business undergraduates at this university are required to take BCOM classes. Students major in accounting, finance, human resource management, supply chain, global business, marketing, information technology, health care management, and business administration. Consequently, the BCOM teams in this study were more diverse than the engineering teams in terms of student majors and, presumably, their orientation and mindset.

A third important distinction between the cohorts is that the BCOM students typically had more experience working on open-ended large team projects in earlier classes than the engineering students. From their first class at this university, business students work on open-ended team projects in most courses regardless of their focus. Projects vary in length, taking from part to all of the semester, and teams vary from three to seven students, but most business courses at this university require a team project. By the time the business students reached the BCOM courses represented in this study, they were generally quite experienced working in teams on open-ended projects. The engineering students, in contrast, typically had far less experience working in teams on open-ended projects. By the time the engineering students began their Senior Design capstone course, their previous team experience was limited to a few clearly defined class projects with a limited scope or partnering with one or two other students in a laboratory class.

A fourth difference between the engineering and BCOM groups in this study is the greater exposure to leadership, teamwork, management, and similar concepts that the business students have received throughout their prior coursework. From the freshmen seminar to upper-division classes, business students regularly receive exposure to leadership and teamwork concepts. In 
comparison, before the capstone class, the engineering cohorts have focused on developing the engineering discipline's technical skills. In conclusion, the BCOM students had more previous exposure and opportunities than the engineering students to work on open-ended team projects and practice leadership and teamwork skills.

There also are critical dissimilarities in the projects the two groups in this study were assigned. Engineering students received more clearly defined projects from the beginning of the semester, which helps explain the engineers' higher scores in the Purpose and Direction area of the first team health check. In comparison, the BCOM students' projects were more open-ended than defined at the beginning of the study. BCOM teams learned that they would choose a significant social need to address, develop a plan to mitigate the problem, and identify a company that would help fund their project. Each BCOM team needed to identify the social need, corporate funder, and idea independently without the instructor's extensive direction. This lack of BCOM project definition correlates with the data shown in Table 2 for Question \#1 on the Eng. \#1 vs. BCOM \# 1 comparison, where the p-value is 0.002 , confirming that the data gathered is statistically significant.

Another interesting result is the decline in the BCOM cohort scores in the Communication category of the Briggs [10] team health check from the first health check to the second. At the first team health check, the mean of BCOM students' scores in the Communication area was 5.46, but the mean at the second team health check had dropped to 5.20. While not a large drop, the decline is worth considering, especially given the points made earlier about the BCOM cohort's previous exposure to leadership and teamwork concepts and prior experience with other open-ended team projects. While it is difficult to define the cause of the drop in BCOM Communication scores, one possible explanation stems from the diversity in the business students' majors and mindsets. Working on an open-ended, challenging project with other students with different orientations and mindsets may have tested BCOM students' teamwork and communication skills.

In comparison, the engineering students who worked on better-defined projects with more similar teammates perhaps did not struggle as much with communication and teamwork. The Communication scores for engineering also dropped (from 5.13 to 5.10), but this is a much smaller decrease than for the BCOM cohort. The possible explanation for the decline in the BCOM students' Communication scores needs further exploration.

As Table 3 shows, Questions 9-12 relate to the team's performance in determining individual team members' roles, teamwork, and decision-making. Except for Question 10 (Team has sufficient resources), the scores for all questions improved. Part of this improvement can be attributed to greater familiarity and time working together. However, we postulate that even these improvements can be related specifically to the additional communications training that the 
Engineering cohort received, which covers team charters, teamwork, and methods to resolve team conflict.

\section{Effect of Cohort Size}

As mentioned above, there were two separate cohorts of engineering students. The first was a Summer/Fall semester class that had about 70 students. The second was a Fall/Spring class that had an enrollment near 240. The small cohort includes data from 51 students, and the large cohort has data from 150 students.

Due to the large difference in size between the two Engineering cohorts, we decided to separate them and compare the Small and Large Engineering cohorts. We also compared the Small and Large Engineering cohorts individually to the overall BCOM cohort to analyze the effect on the results. As is expected, when combined, the large cohort dominates the overall scores. However, when the data is separated by cohort, there are some interesting results.

As seen in Table 4, from the first THC, the overall average score (average across all 19 questions) for the large cohort was 5.11. The small cohort average was 4.98, indicating a higher level of agreement from the large cohort. This tracks with the individual questions, as the large cohort had higher scores on 15 of the 19 questions.

Table 4: Comparison of overall averages, Small and Large Engineering cohorts

\begin{tabular}{|r|c|c|c|}
\hline & First THC & Second THC & Change \\
\cline { 2 - 4 } Small Cohort: & 4.98 & 5.13 & 0.15 \\
Large Cohort: & 5.11 & 5.06 & -0.04 \\
\hline Gap: & 0.125 & 0.069 & \\
\hline
\end{tabular}

After the second THC, we see a dramatic difference. The small cohort now has a higher overall average of 5.13 compared to a lower average of 5.06 for the large cohort. There are several key observations we can draw from this:

- Overall scores improved for the small cohort (4.98 to 5.13) but worsened for the large cohort (5.11 to 5.06).

- The small cohort now has higher scores on 13 of the 19 questions versus 4 of 19 after the first THC.

- The overall change in score was much more significant for the small cohort $(3.44$ times larger).

- The gap in scores between the two cohorts shrunk in half (from .125 to .069). 
Collectively this data points to the higher effectiveness of communications training on small cohorts. This parallels previous research findings [16], [17] that show communications training and other forms of instruction are more effective in smaller groups.

When comparing the Small and Large Engineering cohorts individually to the BCOM cohort, we see additional interesting results. For the Small Engineering cohort (Table 5 below), the gap in overall average was cut in half (as was the gap between the Small and Large Engineering cohorts), dropping from .25 to .11 when compared with BCOM. In Table 6, we see the comparison of the Large Engineering cohort to the BCOM cohort. The gap in overall average increased by $50 \%$ from .12 to .18, and the overall average for the Large Engineering cohort decreased after the second THC. In contrast, the overall average for BCOM increased slightly, explaining the increase in the gap between the two cohorts.

Table 5: Comparison of overall averages, BCOM cohort to Small Engineering cohort

\begin{tabular}{|r|c|c|c|}
\hline & First THC & Second THC & Change \\
\cline { 2 - 4 } BCOM: & 5.23 & 5.24 & 0.01 \\
Small Cohort: & 4.98 & 5.13 & 0.15 \\
\hline Gap: & 0.250 & 0.111 & \\
\hline
\end{tabular}

Table 6: Comparison of overall averages, BCOM cohort to Large Engineering cohort

\begin{tabular}{|r|c|c|c|}
\hline & First THC & Second THC & Change \\
\cline { 2 - 4 } BCOM: & 5.23 & 5.24 & 0.01 \\
\hline Garge Cohort: & 5.11 & 5.06 & -0.05 \\
\hline
\end{tabular}

While the data from the small and large engineering cohorts are different, when applying the ttest to the separate small engineering data, we see that, as shown in Table 2, the same three categories (Processes, Understanding Differences, and Communication) are statically significant for the first THC comparison. We see that the Processes category is still relevant for the second THC, while the Understanding Differences category no longer meets the 0.05 threshold.

Further comparison of the small Engineering cohort and the BCOM cohort shows significant swings in the small Engineering cohort's improvement on Questions 9 and 11-13. This further confirms both the effectiveness of training smaller cohorts and the effect of the communications training on engineering students. 


\section{Implications}

Similar to the smaller engineering cohort, the 105-member BCOM cohort consisted of smaller (35-person) classes. The business students' prior experience working with more than two team members on open-ended projects appeared to help the BCOM cohort in this study navigate some of the areas explored by the Briggs [10] team health check: Team Leadership, Processes, Understanding Differences, and Relationships. However, as previously noted, the drop in the BCOM scores for Communication from the first to second team health checks suggests that business students need more help to communicate well in teams despite their group experience. The three areas related to Communication on the Briggs [10] team health check ask students whether they agree or disagree with these statements:

- Everyone feels their ideas and input are listened to by the rest of the team.

- Differences and conflicts are resolved openly and constructively.

- Members' interactions are open and honest.

Recommended changes in the communication training for the BCOM cohort would be to demonstrate active listening through videos and lectures and then flip the classroom to practice active listening skills with one another. One exercise currently used by one of the authors is to ask students to form pairs and have one person speak about an issue the individual feels passionately about for one minute. The listener can ask clarifying questions but not show value judgments or offer opinions. Student pairs then reverse roles. Next, the same students pair up again, with one student speaking for one minute about the same issue but from the opposing stance. Students then switch roles and rejoin the class to discuss the challenges of listening actively and advocating views that oppose their attitudes and beliefs.

Another tactic that could help business students communicate better while working on undefined, long-term team projects would be to delve deeper into conflict management and negotiating it. Both the BCOM and the engineering cohorts received conflict management training, but a deeper dive into this subject would appear to benefit the business students, in particular.

Finally, business students would benefit from more direct guidance about their projects' scope from the start of the semester. While students see prior teams' work, meet as a team with the instructor, and learn about the various stages of the project, they still apparently struggle with the lack of defined scope in the project. Perhaps the BCOM curriculum needs to adopt the engineering model of more clearly defined projects to ensure better student outcomes.

Overall, the data shows that education for engineering students is more effective in smaller groups, as shown by the data above. The improvement in scores for the BCOM cohort, which 
was similar in size to the small Engineering cohort, further confirms this conclusion. In both smaller cohorts, the training seems to be effective compared to each group's before and after THC scores. As all educators know, effectively training a large cohort is challenging. The results from the large Engineering cohort correlate with this understanding. These results suggest that the engineering instructors should consider restructuring the class so that students receive the training in smaller groups.

Regardless of cohort size, targeted communication training creates improvement in Processes and Understanding Differences for engineering students. In general, this would make sense, as engineering students are more focused on the technical requirements for their project and have spent less time working on larger (>2) project teams and open-ended projects than their BCOM counterparts. The additional focus on communication and team dynamics rounds out the education necessary for engineers to be successful on large project teams and overall helps prepare them to be ready for the step into the engineering profession.

\section{Conclusion}

The reported results suggest that comprehensive communication skills training of this sort benefits students in several ways. First, students can learn to function more productively and professionally on project teams. Second, better team functioning can help students improve their teamwork skills. Third, students can improve critical competencies that employers want new hires to possess, such as oral and written communication, teamwork and collaboration skills, and professionalism/work ethic. Fourth, we discovered that the training is far more effective on smaller cohorts of students.

Moreover, based on the responses, there are lessons that each discipline can learn from the other. The BCOM course curriculum would benefit by better defining their projects from the beginning (the category they lagged in initially). The engineering capstone course would benefit by having students work on open-ended projects and larger project teams earlier in their academic careers to improve the categories that engineering lagged in on the first survey. Overall, by incorporating communication training into both engineering and business communication courses, educators can help their students prepare for the professional workplaces they soon will enter.

We feel that further research into the effects of communication training on students from engineering and other disciplines is warranted. A longitudinal study of the long-term effects of this kind of training on students' professional careers would provide additional insight into the training's overall effectiveness for different disciplines. 


\section{References}

[1] A. G. Eggleston and R. J. Rabb, "Technical communication for engineers: Improving professional and technical skills," in Technological and Engineering Literacy/Philosophy of Engineering Division, ASEE Annual Conference and Exposition, Salt Lake City, Utah, USA, June 24-27, 2018. [Online]. Available: https://www.asee.org/public/conferences/106/papers/23382/view. [Accessed Dec. 29, 2019].

[2] T. Polk, M. Smallwood, J. Sluder, R. Hart and J. Pacheco, "The impact of professional communications training on teamwork and leadership skills," in Conference proceedings of ASEE Annual Conference \& Exposition, Columbus, Ohio, USA, June 25-28, 2017. [Online]. Available: https://www.asee.org/public/conferences/78/papers/19974/view. [Accessed May 28, 2021].

[3] National Association of Colleges and Employers, "The four career competencies employers value most, ” March 29, 2019. [Online]. Available:

https://www.naceweb.org/career-readiness/competencies/the-four-career-competenciesemployers-value-. [Accessed December 29, 2019].

[4] College Simply, "Racial demographics \& diversity," 2019. [Online]. Available: https://www.collegesimply.com/colleges. [Accessed Dec. 29, 2019].

[5] P. L. Cox and P. E. Bobrowski, "The team charter assignment: Improving the effectiveness of classroom teams," The Journal of Behavioral \& Applied Management, vol. 1, pp. 93-108, 2016.

[6] L. Riebe, D. Roepen, B. Santarelli and G. Marchioro, "Teamwork: Effectively teaching an employability skill," Education + Training, vol. 52, pp. 528-539, 2010.

[7] D. J. P. Phillips, "How to avoid death by PowerPoint," YouTube, April 14, 2014 [Video file]. Available: https://www.youtube.com/watch?v=Iwpi1Lm6dFo\#action=share. [Accessed January 12, 2020].

[8] A. E. Stuart, "Engaging the audience: Developing presentation skills in science students," The Journal of Undergraduate Neuroscience Education: JUNE: a publication of FUN, Faculty for Undergraduate Neuroscience, vol. 12, pp. A4-A10, 2013.

[9] B.W. Tuckman and M.A. Jensen, "Stages of small-group development revisited," Group \& Organization Management, vol. 2, pp. 419-427, 1977.

[10] C. Briggs. "A team health check," 2012.

[11] H. Kniberg, "Squad Health Check model - visualizing what to improve," Spotify Labs, Sept. 16, 2014. [Online]. Available: https://labs.spotify.com/2014/09/16/squad-healthcheck-model. [Accessed January 12, 2020].

[12] J. Janlen, "Health checks for teams and leadership," Crisp's Blog, March 11, 2019. [Online]. Available: https://blog.crisp.se/2019/03/11/jimmyjanlen/health-checks-forteams-and-leadership. [Accessed January 12, 2020].

[13] Atlassian, "Health monitors," Team Playbook, 2020. [Online]. Available: https://www.atlassian.com/team-playbook/health-monitor. [Accessed January 12, 2020]. 
[14] Team Retro, "Team radars and health checks," GroupMap Technology Pty, Ltd., 2019. [Online]. Available: https://www.teamretro.com/health-checks. [Accessed January 12, 2020].

[15] T. Gott, T. Bauer, and K. Long, "Student leadership today, professional employment tomorrow," New Directions for Student Leadership, pp. 91-109, May 8, 2019.

[16] F. Moshiri and P. Cardon, "The state of Business Communication classes: A national survey," Business and Professional Communication Quarterly, vol.77 (3), pp. 312-329, 2014. DOI: $10.1177 / 2329490614538489$

[17] M.S. Doran and S. Golen, "Identifying communication barriers to learning in large group accounting instruction," Journal of Education for Business, vol. 73 (4), pp. 221-224, March/April 1998. DOI: 10.1080/08832329809601634 


\section{Appendix}

Name:

Team:

\section{A Team Health Check}

This health check is designed to help teams review their effectiveness. Use the descriptions below to score your personal assessment of the way that team is working right now. For each lettered statement below, you need to give a rating between 1 and 6 .

SCORING

$6=$ Strongly Agree. Fully operational and exceeds the description.

$5=$ Agree. Operational and meets all or nearly all aspects of the description, but not ideal.

4= Slightly Agree. Operational, but incomplete. Partially meets the description.

3 = Slightly Disagree. Nearly operational, but some way to go. Doesn't really meet the description.

$2=$ Disagree. We have started on this, but there is a long way to go. The descriptors do not apply. $1=$ Strongly Disagree. Nothing has been done - this does not apply at all to our team.

\section{Purpose/Direction}

1. The team has a clear mission/purpose, known by all team members.

2. The team has a vision and success criteria which are challenging, meaningful, and exciting.

3. The team understands how the work of the team fits into the larger picture.

\section{Team Leadership}

4. Balances appropriate direction with support and openness.

5. Discusses key issues with the team.

6. Delegates responsibility and leadership to individuals in their area of expertise.

\section{Processes}

7. Team meetings are effective.

8. The team has found and implemented better ways of working.

9. The team has an efficient process to solve problems and make decisions.

10. The team has sufficient resources (people, money, time) to do its work.

\section{Understanding Differences}

11. Team members understand what their roles are and where these overlap with others' roles.

12. Team members are clear about what is expected of them individually by the rest of the team.

13. Team members are clear about what individual strengths each member of the team brings. 


\section{Communication}

14. Everyone feels their ideas and input are listened to by the rest of the team.

15. Differences and conflicts are resolved openly and constructively.

16. Members' interactions are open and honest.

\section{Relationships}

17. The team's different experiences, skills and gifts are accepted and used.

18. There is trust and openness between team members.

* New members feel valuated and quickly become productive members of the team.

19. The team takes responsibility for its successes and failures and avoids blaming others.

Adapted from "Team Building” by Dr. Cindy Briggs, 2012

*This question was omitted since team membership does not change during the course. 